\title{
Research on the Construction of Teaching Quality Index of Teachers in Higher Vocational Colleges
}

\author{
Zhimin Liu, Yuemin Teng \\ Shanghai Publishing and Printing College, Shanghai, China \\ Email: qiierrsann@163.com
}

How to cite this paper: Liu, Z.M. and Teng, Y.M. (2020) Research on the Construction of Teaching Quality Index of Teachers in Higher Vocational Colleges. Open Access Library Journal, 7: e6242.

https://doi.org/10.4236/oalib.1106242

Received: March 18, 2020

Accepted: April 20, 2020

Published: April 23, 2020

Copyright $\odot 2020$ by author(s) and Open Access Library Inc.

This work is licensed under the Creative Commons Attribution International License (CC BY 4.0).

http://creativecommons.org/licenses/by/4.0/

\section{(c) (i) Open Access}

\begin{abstract}
Based on the study of other social evaluation indexes, this paper studies the management and control of teaching quality by using the research methods of system science, aiming to find a calculation method that can comprehensively reflect the overall quality characteristics of the teaching system. On this basis, the paper puts forward the construction scheme of Higher Vocational Education Teachers' teaching quality index, which includes five dimensions such as student attendance data, student evaluation data, supervision data, peer evaluation data, management organization inspection data and several observation indexes. At the same time, a comprehensive empirical analysis is made on the 2019 teachers' teaching quality index of our school. The average teaching quality index of teachers is 86.0 , indicating that the quality is in a good state.
\end{abstract}

\section{Subject Areas}

Education

\section{Keywords}

Teaching Quality Index, Evaluation Dimension, Set Up, Higher Vocational Colleges

\section{1. 引言}

我国高等职业教育驶入快车道, 如何保证高等职业教育的教学质量具有非常 重要的意义。高等职业教育教学质量指数构建是一个复杂系统, 包括多个层 次和多个指标, 对这个问题的研究是一个具有开创性的探索性课题。高等职 业教育的教学质量指数可以较为方便地评估高职院校的教学质量和高技能人 才的培养水平。这些数据可为各级教育部门和高职院校制定高等职业教育发 展规划和实施教育教学质量监管提供简洁可靠的决策依据。如何制定及评定 
教学质量指数的客观评价标准是对我们教育工作者提出的一个现实课题。本 文在研究其它社会评价指数的基础上, 应用系统科学的研究方法研究教学质 量的管理和控制, 旨在寻找一个能综合地、全面地反映教学系统的总体质量 特性的计算方法。在此基础上, 提出了高等职业教育教师教学质量指数构建 方案, 包括学生出勤数据、学生评教数据、督导听课数据、同行评价数据、 管理机构巡查数据等五个维度以及若干观测指标。并对上海出版印刷高等专 科学校 2019 年教师教学质量指数进行了综合实证分析, 教师的教学质量指数 平均为 86.0, 表明质量处于较好状态。通过这些数据, 我们也可以找出从哪 些方面入手来提高或优化我们的教师教学质量。

\section{2. 教学质量指数维度构建}

指数的构建研究始于社会发展领域, 在上个世纪 50 年代, 社会发展领域指数 研究蓬勃兴起。其初衷是研究政府所制定的社会发展目标的完成情况, 研究 结果对政府的决策过程的合理性和政策执行效果具有良好的导向作用[1] [2] [3]。Corbett 对指数问题进行了深入研究, 并认为指数有四种职能, 即监测、 政策制定、结果评估、评价问责等, 有些研究人员还认为指数还具有提高政 策执行力的功能[4] [5] [6]。美国加州大学伯克利分校 Bauer 认为指数是一些 包含证据的原始数据及其统计结果, 这些数据可以让我们对比要实现的目标 知道我们现在处于什么阶段、想要达到什么阶段并确定执行过程的影响 [7]。 在对指数的逐步研究过程中促进了研究者对指数的系统探索。联合国开发计 划署于 1990 年提出了即人类发展指数[8], 包括预期寿命, 受教育程度和生活 水平三个维度。经济合作与发展组织 OECD 于 2011 年正式推出 YBLI 生活质 量指数概念, 该指数纠正了单纯使用 GDP 对生活质量进行评价的片面性, 该 指数包括两个二级指标和十一个三级指标[9]。为评估国家与经济体创新的方 法和途径, 康奈尔大学和世界知识产权组织等机构共同研制了全球创新指数 (GII), 每年发布一次[10]。上述人类发展指数、生活质量指数和全球创新指 数研究理念、方法并非完美, 但其蕴含的认识和思路对构建高职院校教师教 学质量指数具有重要的启示和方法论意义。

教师教学质量指数评价设计多层次和多个指标, 过程较为复杂, 同时教师 的教学质量评价也是一个相对的过程。经过多次调研, 我们从学生出勤数据、 学生评教数据、督导听课数据、同行评价数据、管理机构巡查数据 5 个维度 反映教师教学质量, 每个维度下列多个指标, 并使采样数据具有导向性、可 获得性、针对性等原则, 优化后形成的教师教学质量指数框架如图 1 所示。

对各项评价指标的规定: (1) 学生出勤率: 根据教师所教授的课程每学期学 生的出勤记录。(2) 学生评教: 该评价项目包括学习效果、教学方法、教学内 容、互动交流、教学手段和教学资源。(3) 督导听课: 该评价项目包括教学效 果、教学方法、教学内容、教学态度、学生表现和教学条件。(4) 同行评价: 该评价项目包括教学效果、教学方法、教学内容、考核方式。(5) 管理员巡查: 该评价项目包括教学秩序、教学态度、课堂效果和教学条件。

\section{3. 阈值选择及维度指数计算方法}

阈值选择及维度指数计算方法: 1) 学生出勤率: 结合本门课程本学期统计数 据, 确定学生出勤率指数 $=$ [本学期本门课程实到人次/本学期本门课程应到 人次 $] \times 100$ 。 


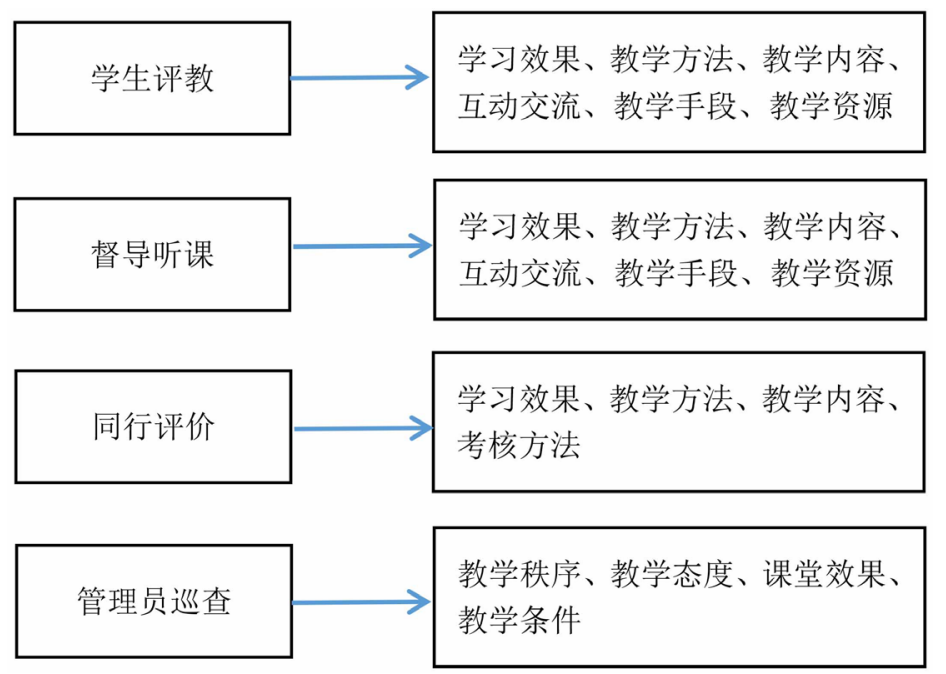

图 1. 教师教学质量评价维度。

2) 学生评教指数: 学生在进行网上评教时, 要对其下面的各项指标进行打 分, 系统自动生成总分数, 教师评教指数 $=\frac{\sum_{i=1}^{n} s_{i}}{n}$, 其中 $n$ 为参与评教的学 生人数, $s_{i}, i=1,2, \cdots, n$ 为第 $i$ 位学生的评教成绩。

3) 督导评教指数: 督导在进行评教时, 要对督导评价指标下面的各项二阶 指标进行打分, 汇总督导评教结果, 督导评教指数 $=\frac{\sum_{i=1}^{n} s_{i}}{n}$, 其中 $n$ 为参与 评教的督导人数, $s_{i}, i=1,2, \cdots, n$ 为第 $i$ 位督导的评教成绩。

4) 同行评价和管理员巡查的评价指数和学生评教以及督导评教的评价指 数相似, 计算方法相同。

以上所有质量指数计算结果精确到十分位, 质量指数合成规则及计算方法: 根据专家的调研结果, 会给每个质量指数维度赋予一定的权重 $w_{i}, i=1,2,3, \cdots, 5$ 综合质量指数的计算方法如下:

$$
\text { 综合质量指数 }=\sum_{i=1}^{5} w_{i} p_{i},
$$

其中 $p_{i}$ 为第 $i$ 个评价维度的质量指数。

在评价操作阶段, 综合专家的调查意见, 各维度的权重值设为 $0.2,0.2,0.25$, $0.25,0.1$ 。根据该权重对上海出版印刷高等专科学校的历年教学质量数据进行 评估。根据上海出版印刷高等专科学校历年的教学质量评价各等级的比例设 置标准, 计算历年教学质量的指数数据, 将综合质量指数计算值高于 90 分时, 认定为 “优秀” 等级; 综合质量指数大于 80 小于等于 90 时, 认定为 “良好” 等级; 综合质量评价指数大于 70 小于等于 80 时, 认定为 “一般” 等级; 综 合质量评价指数大于 60 小于等于 70 时, 认定为 “合格” 等级。综合质量评 价指数低于 60 时, 认定为 “不合格” 等级。

\section{4. 教师教学质量指数计算模型应用}

跟据前述部分构建的教师教学质量指数架构和评价方法, 我们以 2019 2020 
学年上海出版印刷高等专科学校第一学期作为数据采样时长, 通过计算得出 学生出勤指数为 88.4、学生评教评价指数为 85.9、学校督导评价指数为 89.1、 同行评价指数为 92、管理员巡查指数为 90.7。通过五种维度指数的合成计算 方式, 可得 2019 2020 年我校教师教学质量指数为 87.9, 表明我校教师教学 质量位于良好的运行状态, 且构成教学质量评价的五个维度之间基本比较平 衡, 说明我校的教师教学质量总体处于较好水平。

\section{5. 结语}

本文参考了各类社会发展评价指数, 对高职院校的教师教学质量评价进行了 研究型的探索，基于维度选取合理、结构层次分明、数据采集简单、计算方 法客观的思路, 对教师教学质量指数的评价问题进行优化, 并提出了构建方 案。根据所提出的教师教学质量指数评价维度和计算方法, 可以便捷地计算 得出学期或年度教师教学质量指数, 教师教学质量指数可回应社会大众对高 等教育教学质量的关心, 并可作为对教师教学质量进行监测评估的重要依据, 从而为各级教育行政部门和各高等学校制定教师教学质量发展政策和高等教 育教学质量保障措施提供参考依据。目前教师教学质量指数在我国范围内可 以进行有意义的纵向比较, 很难在国际范围内与其他国家同层次教育开展横 向比较。所以, 教师的教学质量指数还需要进一步完善, 我们认为可以在三 个方面进行优化提升, 首先要进一步树立科学的教师教学质量观, 使教学质 量指数的评价维度更加贴近教学质量的内涵, 使所设置的数据采集指标能反 映和体现教学质量利益相关者的核心需求; 二是要借鉴利用大数据相关技术, 从基础指标调整、采样数据收集、评价方式及结果呈现等方面对教师教学质 量指数的维度构建和观测指标进行适时优化; 三是要面向全球, 在国际化视 角下审视我们的教师教学质量, 在与其它国家对比的基础上, 使评价维度体 现出中国特色, 又体现出国际视野, 构建教学质量国内、国际均可比较的维 度体系, 为我国的教师教学质量监测评估设立国际坐标。

\section{Conflicts of Interest}

The authors declare no conflicts of interest regarding the publication of this paper.

\section{References}

[1] 霍德利, 刘龙飞, 袁野, 陈学铭, 赵杪涁. 基于熵权法北京冬奥会社会风险预警 指标权重研究[J]. 沈阳体育学院学报, 2019, 38(5): 47-55.

[2] 胡国强, 七顺超. 基于层次分析法和摘权法的高校教师教学质量评价一一以学生 评价教师为例[J]. 内蒙古师范大学学报(教育科学版), 2019(8): 62-66.

[3] 王欣, 王㴋雅. 基于二元语义和熵权法的教师课堂教学质量评价[J]. 商洛学院学 报. 2019, 33(4): 65-68.

[4] 雷勋平, 刘晨. 摘权法在高校实践教学质量评价中的应用[J]. 蚌埠学院学报, 2015, 4(6): 125-128.

[5] 李望晨, 李伟, 刘建兰, 贺圣文. 基于组合摘权灰色关联分析法的医学教学质量 评价[J]. 数理医药学杂志, 2014(4): 5451-452.

[6] 尹鹏, 杨仁树, 丁日佳, 王文博. 基于熵权法的房地产项目建筑质量评价 [J]. 技 术经济与管理研究. 2013(3): 3-7. 
[7] 黄玲青, 唐闪光. 高职院校教学质量评价体系构建研究 [J]. 教育与职业. 2011(29): 21-22.

[8] 刘晓敏. 高职教育教学评价的现状 问题与对策的研究 [J]. 中国职业技术教育. 2005(11): 53-55.

[9] 胡秀锦. 高职高专教学质量监控和评价的几点思考 [J]. 职业技术教育. 2003, 24(34): 30-32.

[10] 王晓江, 祝西莹, 张普礼, 王兆奇. 高职教学质量监控与评价体系研究与实践 ——系(部)教学质量监控与评价办法[J]. 职业技术教育, 2003, 24(13): 26-28. 